\title{
Orientação para o emprego e renda - Necessidades dos estudantes universitários brasileiros
}

\author{
Employment and income - Brazilian college students needs
}

\author{
Suely Aparecida do Nascimento Mascarenhas* \\ *Universidade Federal do Amazonas, Brasil
}

\begin{abstract}
Resumo
O ensino superior dentre suas funções educativas tem a responsabilidade de prestar orientações para os estudantes acerca das oportunidades de ocupação profissional e geração de renda. A pesquisa foi realizada com apoio do CNPq em três universidades públicas com a participação de $n=1590$ estudantes do sexo masculino e feminino. Os estudantes demonstraram necessitar de mais orientação sobre as saídas profissionais e as possibilidades de emprego. Da análise dos resultados, conclui-se sobre a acentuada necessidade que os estudantes possuem de receber mais orientação e assessoramento da universidade sobre as possíveis saídas profissionais e oportunidades de emprego.
\end{abstract}

Palavras chave: orientação para o emprego, ensino superior, estudantes universitários.

A orientação educativa formal realizada no contexto escolar é responsável por informar às novas gerações sobre as necessidade de desenvolvimento pessoal tendo em vista a construção de competências para a inserção socioeconômica e autonomia pessoal e profissional no contexto social.

$\mathrm{O}$ assessoramento aos estudantes em geral e em especial os do ensino superior abrange cada vez mais novos âmbitos de ação e decisão no curso da educação, formação, profissão e práxis de vida. Em geral requerem assessoramento tendo em consideração a complexidade crescente em todos os âmbitos da vida em sociedade. A finalidade do assessoramento é capacitar para a autoajuda através de informações, consultas esclarecedoras, palestras, apoio para elaboração conjunta de ajuda para a tomada de decisões. Entra as formas de assessoramento mais conhecidas destacam-se o assessoramento educativo; o assessoramento profissional; o assessoramento matrimonial e o assessoramento escolar.

O processo de assessoramento pode se subdividir em vários passos: a) esclarecimento do desejo; b) desenvolvimento de diferentes enfoques de solução; c) Busca de informações relevantes para a tomada de decisão; d) avaliação conjunta da tomada de decisão; e) apoio para o processo de decisão e f) oferecimento de ajuda para a realização da solução.

$\mathrm{O}$ assessoramento acadêmico refere-se à atividade institucional de faculdades e universidade possuem de informar aos estudantes que desejam iniciar uma carreira e ao que fazer para desenvolverem-se no contexto universitário no que se refere às possibilidades de estudo, conteúdos específicos, estruturação e exigências da carreira. Em ocasiões estas tarefas incluem o apoio aos estudantes durante o estudo com palestras e atividades informativas de acompanhamento e assessoramento.

O assessoramento na universidade é uma necessidade que se centra especialmente no início do curso e durantes os primeiros semestres, abordando questões de possibilidades acadêmicas, requisitos de organização dos estudos, condições de permanência. Dado o processo de democratização do ingresso na universidade, cresce a importância da orientação e apoio aos estudantes com condições econômicas desfavorecidas de modo a garantir sua permanência e sucesso por meio da oferta de bolsas e ajudas sociais e econômicas bem como transição para o trabalho dentre outras ações de inserção socioeconômica (Schaub \& Zenke, 2001).

O cenário da América Latina, onde se situa o Brasil e em especial o contexto da Região Norte e Centro Oeste onde essa pesquisa foi realizada, materializa uma realidade de baixos indicadores de desenvolvimento social e econômico. O que requer uma aliança entre a pedagogia universitária, a pedagogia social e quiçá a psicopedagogia universitária e psicopedagogia social tendo em vista apoiar os estudantes na permanência e sucesso acadêmico na universidade.

A atividade de assessoramento e orientação no contexto universitário pode apoiar-se numa perspectiva de psicopedagogia social que centra-se em oferta de cuidado, assessoramento e apoio familiar nos âmbitos escolares a estudantes ameaçados em desenvolvimento pelas desvantagens históricas e perigos sociais aos quais estão sujeitos. A concepção configura um sistema de ajudas psicossociais e materiais para todos os que precisam de apoio temporário ou duradouro no âmbito das demandas sociais, econômicas e de ordenamento político. Tem como focos: a) reforçar indivíduos e 
grupos em sua auto responsabilidade e competência para a ação, por maio de assessoramento e ofertas de oportunidades para aprendizagem social bem como ajuda para solucionar conflitos e crises centradas em problemas pontuais. E por outro lado, cooperar com a melhoria política do marco de condições sociais e econômicas que redundará em benefícios para uma vida autodeterminada e satisfatória (Schaub \& Zenke, 2001).

Para a realização do assessoramento no ensino superior, se faz necessária a estruturação institucional de serviços multiprofissionais que possam realizar as atividades. Tais profissionais (professores, psicopedagogos, psicólogos, pedagogos, assistentes sociais, fonoaudiólogos, e outros profissionais afins) têm a competência de realizar dentre outras, tarefas como: análise e assessoramento relacionado à aprendizagem, dificuldades de rendimento acadêmico, problemas de conduta, conselho quanto ao curso escolhido, assessoramento no caso de conflitos com professores, estudantes. Por outro lado, também são responsáveis por ofertar apoio técnico-pedagógico a professores, direção, técnicos administrativos com relação a aspectos pedagógicos em geral que tenha como meta o sucesso acadêmico em especial associadas a medidas disciplinares e piscopedagógicas (Schaub \& Zenke, 2001).

No geral a orientação pode ser necessária para indivíduos em determinados momentos de sua carreira. Na perspectiva dos educadores, quanto mais pessoas puderem beneficiar-se com Serviços de Orientação qualificados e desenvolvidos por técnicos competentes e credenciados, melhor será para o desenvolvimento da carreira pessoal e profissional dos cidadãos e para o país.

No âmbito do ensino superior brasileiro, a procura de estudantes por universidades públicas é muito grande, pois além do fator econômico que leva a essa busca, a qualidade é reconhecida nacional e internacionalmente. A universidade constitui-se em espaço de manutenção do status da classe média alta e, por outro lado, em possibilidade de ascensão social de pessoas da classe média baixa e classe baixa que conseguem romper as barreiras ritualizadas do vestibular e outros procedimentos de seleção para o ingresso no ensino superior público (Teixeira, 1981). Ao ingressar no ensino superior e ao longo do curso o estudante que conta com o apoio psicopedagógico do serviço de orientação acadêmica reúne melhores condições de obter o sucesso almejado com a conclusão do curso e o ingresso no mercado de trabalho.

O serviço no âmbito institucional tem funções específicas como a intervenção psicopedagógica, utilizando métodos, instrumentos e técnicas próprias da psicopedagogia proporciona medidas permanentes de atendimento aos alunos, incluindo orientação acadêmica no que diz respeito à sua vida escolar e à sua aprendizagem; proporciona atendimento aos professores no que diz respeito a esclarecimentos sobre a didática do ensino; atende aos funcionários com esclarecimentos; oferece acompanhamento didático pedagógico aos docentes; orienta trabalhos de pesquisa e oferece suporte técnico aos acadêmicos monografistas. O Núcleo de Orientação Psicopedagógica trabalha de forma personalizada, assegurando o sigilo absoluto como forma de preservar a identidade do participante.

Suas competências, no que se refere ao acadêmico, são:

1. Orientar o iniciante a aproveitar ao máximo seus estudos;

2. Auxiliar o iniciante a compreender a universidade e a se ajustar às novas condições de estudo;

3. Localizar deficiências de formação do novato e providenciar atividades de nivelamento, a fim de que não venha a sentir maiores dificuldades em seus estudos;

4. Cooperar na solução de possíveis dificuldades com colegas, professores e outras pessoas envolvidas no processo ensino-estudo-aprendizagem;

5. Prestar esclarecimentos profissionais, ao acadêmico, com relação ao curso escolhido e à vida acadêmica;

6. Auxiliar o acadêmico das diferentes séries, na busca de solução, quando tem problema que afeta a sua progressão satisfatória em seus estudos;

7. Registrar ocorrências sobre a vida acadêmica do discente, dando ciência ao mesmo;

8. Realizar levantamento de atividades preventivas que se destinam a prevenir possíveis causas de insucesso acadêmico;

A inserção de uma visão psicopedagógica no ensino superior é uma necessidade para a diminuição das tensões e problemas que acontecem nesse âmbito de ensino, que podem se transformar em práxis educativas inovadoras e renovadoras de esperanças, sucessos pessoais e profissionais. Pois também no ensino superior os estudantes apresentam demandas específicas relacionadas aos vínculos com a aprendizagem, com os docentes e com os colegas de classe, integração a grupos. Deste modo, assumir e assimilar a cultura universitária pode ser uma tarefa difícil para alguns estudantes, além de dificuldades em vários níveis: socioeconômicos, sociocognitivos, dilemas familiares, pessoais, emocionais e afetivos, aos quais não raros, os fazem parar de aprender ou bloquear e que exigem intervenções institucionais apoiada em políticas de apoio aos estudantes de modo a possibilitar sua permanência e sucesso neste contexto de inclusão social e econômica que é a universidade.

Em suma o serviço de orientação acadêmica tem a finalidade de oferecer recursos que o auxilie o estudante universitário no desempenho de sua a atividade educativa como também a compreensão das relações intersubjetivas entre aluno-professor-disciplina, em situação acadêmica resultante de um complexo conjunto de influências psicológicas, sociais, formais e informais.

Neste artigo, temos como objetivo descrever as necessidades dos estudantes universitários brasileiros de receber por parte da universidade assessoramento e orientação acadêmica para apoiar o sucesso e a inserção 
no mercado de trabalho de modo a contribuir com sua realização profissional e pessoal em sentido amplo (Mascarenhas \& Col., 2012).

\section{MÉTODO}

\section{Participantes}

A pesquisa foi realizada com apoio do CNPq (Edital Universal 2009-2012) em três universidades públicas federais brasileiras (UFAM, UNIR e UFGD), contando com a participação de $n=1590$ estudantes do sexo masculino e feminino, matriculados de cursos de diversas áreas do conhecimento que responderam a instrumento próprio observando procedimentos éticos vigentes.

Os resultados indicam que os mesmos são pertencentes a diferentes classes sociais sendo que 5,7\% possuem renda familiar menor que um salário mínimo; 19,9\% um salário mínimo; 35\% de dois a três salários mínimos 14,4\% até cinco salários mínimos; 16,1\% mais de cinco salários mínimos e 8,9\% não informou a renda familiar. $\mathrm{O}$ que sugere uma predominância de estudantes integrantes das classes menos favorecidas economicamente.

O acesso e o sucesso no ensino superior é um indicador importante na formação profissional, que influencia as oportunidades de mobilidade social; considerando que os profissionais graduados tendem a receber melhores ofertas de emprego e renda

\section{Instrumento}

O instrumento utilizado foi o Questionário sobre necessidades de orientação na universidade (ARZA, 2009), constituído por 23 itens sendo 1 aberto. Os itens estão organizados numa escala likert de 5 pontos. Sendo 1. nenhuma e 5. muita.

\section{Procedimentos de coleta, tratamento e análise de dados}

Os participantes responderam ao instrumento anônima e voluntariamente em horário de aula, previamente agendado cedido pelos professores com acompanhamento de equipe treinada, observando procedimentos éticos internacionais vigentes. O tratamento foi realizado com apoio do SPSS e analisado de acordo com os objetivos da pesquisa no LAPESAM, Grupo de Pesquisa-UFAM/CNPq.

\section{RESULTADO E DISCUSSÃO}

O acesso e o sucesso no ensino superior é um indicador importante na formação profissional, que influencia as oportunidades de mobilidade social; considerando que os profissionais graduados tendem a receber melhores ofertas de emprego e renda. Acerca da "orientação recebida sobre assessoramento e conselho sobre as saídas profissionais e as possibilidades de emprego" $\mathrm{M}=2,44$; $\mathrm{DP}=1,16$; e quanto à "orientação que necessita sobre assessoramento e conselho sobre as saídas profissionais e as possibilidades de emprego" $\mathrm{M}=$ 3,$21 ; \mathrm{DP}=1,36$.

Os indicadores revelam necessidade de orientação para geração de emprego e renda de modo a apoiar a inserção laboral dos estudantes universitários após a conclusão do curso.

Assim, apontamos para a necessidade de se estruturarem políticas públicas para a implantação de Serviços de Orientação consistentes em suas funções e objetivos que promovam trabalhos de apoio efetivo ao estudante em todos os aspectos, sejam eles cognitivos, psicológicos e/ou sociais, contribuindo assim, para uma formação superior mais humanista e completa, realmente mais efetiva para o desenvolvimento pleno do indivíduo.

Neste sentido, o trabalho em conjunto entre o pedagogo, na função de orientador educacional, o psicólogo e demais profissionais nas instituições de ensino é de fundamental importância; pois podem discutir e preparar, em conjunto, os respectivos planos de ação, destacando que as relações profissionais no âmbito de cada profissão devem ser esclarecidas e respeitadas, cada qual atuando nos limites de suas atribuições e participando também das atribuições do outro para a obtenção dos objetivos comuns propostos.

\section{CONCLUSÃO}

Da análise dos resultados, conclui-se sobre a acentuada necessidade que os estudantes possuem de receber mais orientação e assessoramento da universidade sobre as possíveis saídas profissionais e oportunidades de emprego. Esse conhecimento pode contribuir com a criação de programas e políticas próprias de orientação para o emprego no ensino superior brasileiro.

O ensino superior constitui-se num campo de trabalho privilegiado para o Psicólogo Escolar, Psicopedagogos, Pedagogos, Assistentes Sociais, Médicos, dentre outros, devido à ausência de programas de apoio ao estudante e tutoria, o que pode contribuir para a perpetuação de dificuldades de várias ordens, como formação básica insuficiente, falta de habilidades de leitura, escrita e estudo, insegurança nas tomadas de decisões. Tais fatores evidenciam a necessidade da atuação do psicólogo escolar, do psicopedagogo, do assistente social, do professor tutor e outros profissionais de acordo com o perfil dos estudantes e do contexto universitário em causa.

A continuidade de pesquisas e publicações na área poderá ampliar a oferta de mais informações sistematizadas sobre o tema.

\section{Agradecimento:}

A autora agradece aos colaboradores da UFAM e UNIR, aos participantes da pesquisa, o apoio financeiro do $\mathrm{CNPq}$ ao projeto bem como a colaboração da $\mathrm{Dr}^{\mathrm{a}}$ Neves Arza Arza da Universidade da Corunha, Espanha na disponibilização do instrumento de coleta de dados e assessoramento. 


\section{REFERÊNCIAS}

Arza A, A.N. (2009). Questionário avaliação de necessidades de orientação no ensino superior, Universidade da Corunha, /Tradução Mascarenhas, S.. PROJETO DE PESQUISA: AVALIAÇÃO DE VARIÁVEIS COGNITIVAS E CONTEXTUAIS ORIENTAÇÃO EDUCATIVA, HÁBITOS DE ESTUDOS, ESTRESSE, ANSIEDADE E DEPRESSÃO - INTERFERENTES NO RENDIMENTO DE ESTUDANTES DO ENSINO SUPERIOR DO AMAZONAS E DO MATO GROSSO DO SUL - apoio CNPq edital 2/2009 - Processo 401468/2009-7 2009, UFAM/IEAA-HUMAITÁ, AM.

Chaves, F. M. R. (2015). Orientação Psicopedagógica no Ensino Superior: uma experiência inovadora, disponível em: http://www.fdvmg.edu.br/coluna-do-professor/artigoorientacao-psicopedagogica-no-ensino-superior-umaexperiencia-inovadora-17 - Acesso 10-06-2015

Mascarenhas, S. A. do N., Gutierrez, D.M. D., Lira, R., Arza, N. A, Calejon, L.M. C., Fariñas-León, G. \& Machado, L. (2013). Orientação e apoio social aos estudantes do ensino superior e rendimento acadêmico, pág.135-144. In. Mascarenhas, S. A. do N. (Coord.) Determinantes do Rendimento Acadêmico no Ensino Superior, São Paulo, Loyola.

Mascarenhas, S. A. do N., Silva, A. Q. da, Galdino, Z. da C. ,Arza, N. A, Machado L.. \& Brasileiro, T. S. A. (2013). Orientação no ensino superior e rendimento- a função orientadora da universidade, pág.145-153. In. Mascarenhas, S. A. do N. (Coord.) Determinantes do Rendimento Acadêmico no Ensino Superior, São Paulo, Loyola.

Mascarenhas, S. A. do N., Galdino, Z. da C. ,Arza, N. A, Machado L.. \& Brasileiro, T. S. A. (2013). Função Orientadora dos Professores no Ensino Superior e Rendimento Acadêmico, pág.154-163. In. Mascarenhas, S. A. do N. (Coord.) Determinantes do Rendimento Acadêmico no Ensino Superior, São Paulo, Loyola.
Mascarenhas, S. A. do N., Arza, N. A. FariñasLeón, G, Galdino, Z. da C., Gutierrez, D.M. D.,.Silva, G. C. R da \& Peluso, M. L. A. (2013b). Relações entre serviço de orientação educativa/tutoria e rendimento acadêmico no ensino superior, pág.193-213. In. Mascarenhas, S. A. do N. (Coord.) Determinantes do Rendimento e do Bem Estar Psicossocial em Contextos Educativos Formais, São Paulo, Loyola.

Mascarenhas, S. A do N. , Lira, R. de S., Gutierrez, D. M .D. Silva, A. Q. da.,Roazzi,,A., Polydoro, S. A. J., Boruchovitch, E. Arza, N. A. \& Ribeiro, J. L. P. Relatório do Projeto de Pesquisa Avaliação de variáveis cognitivas e contextuais orientação educativa, hábitos de estudos, estresse, ansiedade e depressão - interferentes no rendimento acadêmico de estudantes do ensino superior do Amazonas e do Mato Grosso do Sul. Edital 2/2009CNPq, processo 401468, Humaitá, Amazonas, Brasil, 2010-2012.

Melo-Silva, L. L.; Lassance, M.C.P. \& Soares,; D. H. P. (2004). A orientação profissional no contexto da educação e trabalho, in Revista Brasileira de Orientação Profissional, ISSN 1679-3390, Vol. 6, n 2, pag.31-52.

Schaub, H. \& Zenke, K. G. (2001). Diccionario Akal de Pedagogía, Madrid, Akal Ediciones S.A.

Teixeira, S. A. (1981). Vestibular: ritual de passagem ou barreira ritualizada.Ciência e Cultura, 33(12), 1574-1580. 